\section{Electronic Theses: their production, management and use.}

\section{Susan Copeland}

\author{
T. \\ Susan Copeland is currently Acting Depute Librarian at \\ The Robert Gordon University in Aberdeen. She is a \\ graduate of the universities of St.Andrews, Wales, and \\ Sheffield and, prior to being appointed Senior Librarian at \\ RGU in 1990, she worked in school and public library \\ services.e-mail: s.copeland@rgu.ac.uk
}

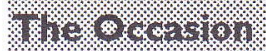

This study resulted from the Group's 1997 Elsevier/LIRG Research Award.

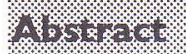

This article presents the findings of a research visit to the USA which was undertaken, in 1998, to assess the production, management and use of electronic theses at Virginia Polytechnic Institute and State University (Virginia Tech.).The activities there, and the achievements of the Networked Digital Library of Theses and Dissertations (NDLTD) project, are contrasted with the efforts of the University Theses Online Group (UTOG) in the UK. A year on from the visit, the electronic theses atVirginia Tech. are being consulted more than before. In contrast, in the UK, interest still appears tó be limited.
\end{abstract}

This article aims to demonstrate the value of producing theses in electronic format, to discuss what is required in order to achieve an acceptance of electronic theses, and to encourage further work in this area.

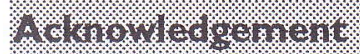

Funding from the 1997 Elsevier/LIRG Research Award, which was much appreciated, enabled the author to visit Virginia Tech., attend the 'Digital Libraries in Practice' workshop at the University of Maryland, and participate in a meeting of the Steering Group of the Networked Digital Library of Theses and Dissertations in Washington D.C. Thanks are due to the following at Virginia Tech. John Eaton (Associate Provost for Graduate Studies), Edward Fox (Professor, Computer Science) and Gail McMillan (Director, Scholarly Communications Project).

\section{Introduction}

In recent years an increasing amount of information has been made available to library users in electronic format. Online access to full-text journals, as well as bibliographic databases, is becoming commonplace, as is the provision of information on Web pages. Library users are beginning to expect instant access to the resources they require, and developments in open and distance learning are necessitating the delivery of information to users in remote locations. In this environment it is perhaps surprising that more has not been achieved with regard to converting university theses into electronic format.

Most libraries are under pressure with regard to shelf space, yet theses have to be kept in accordance with institutional regulations even if many of them are little used. The result is that the collections are often relegated to store areas which may be at some distance from the main library stock - thus leading to delays in providing users with the resources they require. When theses are acquired from other organisations, on inter-library loan, they normally have to be consulted within the receiving library, thus restricting use to those times when the researcher can visit the building. Gaining access to theses which are produced in universities which do not participate in the British Library's British Thesis Service may involve additional efforts. Such difficulties (or perceived difficulties) in obtaining access may result in under-use of these valuable sources of information and, at a time when university research is subject to scrutiny with regard to cost-effectiveness and value-for-money, this is a matter of some concern.

\section{Benefits}

New technologies are providing the means to produce theses electronically, and students, researchers and librarians can all benefit to some degree from these developments. Students benefit from the flexibility of the new media and the opportunity to employ greater creativity in demonstrating their research results e.g. through the incorporation of audio material or three-dimensional images. They also benefit from the acquisition of transferable I.T. skills and savings on the cost of the production. Communication with supervisors who are absent from the university is made easier if the 
Electronic Theses

Susan Copeland

draft thesis is in electronic format and, after a viva, revisions can be made more easily.

If theses are available in electronic format, rather than as paper-based documents, libraries can provide a better service to the researchers who want to refer to them since access can be provided speedily, at any time, and at locations other than the library. One of the most significant advantages is speed of access to theses which have been produced in other countries. Furthermore, online theses can be made available to more than one reader simultaneously and searches by keyword allow the quick and easy location of specific information within the work.

As well as providing improved services to users, libraries benefit from this development in terms of their internal organisation and deployment of resources. They save not only storage space but also staff time since there is no need to retrieve, issue and reshelve physical items. Administrative work can be streamlined and management information provided when required since statistics of use can be obtained easily if theses are accessed via the Internet.

\section{Concerns}

The lack of developments in this area to date, despite the above advantages, may be attributed to a number of factors. The attitude of those who write, supervise, supply and consult theses is significant with regard to the level of demand for change and . the likelihood of success for any project trying to achieve such change. Where there is enthusiasm for the new media, individuals and organisations have to take into account various practical issues:

- the technical infrastructure must be adequate to allow speedy access to online material,

- students must have access to appropriate equipment and software,

- training must be provided for both students and their supervisors, and

- the cost and time involved if users wish to read the end result as a print-out rather than onscreen must be taken into account.

Consideration also has to be given to futureproofing arrangements and archiving requirements for example the potential problems involved if theses contain links to external web sites.
Library \& Information Research News (LIRN)

Volume 23 - Number 75 - Autumn 1999

Various political and legal matters pose difficulties, too, for those trying to achieve the acceptance of theses in electronic format. For instance, university regulations on submission and examination guidelines need to be changed, and concerns about copyright, intellectual property rights and plagiarism have to be addressed. Students need to have the option of either making their thesis available to the public straightaway or denying public access for a specified length of time. In addition, there are implications for the institutions which deposit and borrow items from the British Library's British Thesis Service, and consideration may need to be given to the introduction of a charging mechanism.

\section{U.K. developments}

UTOG: The University Theses Online Group (UTOG) was formed in 1994 to try to respond to the changing circumstances relating to the production and use of theses in the U.K. (1) Its main aim was to promote informed discussion on the subject of electronic theses, with a view to achieving a culture change, i.e. persuading university administrators, research students, their supervisors, and users of the end product, to accept theses in new formats.

Membership of UTOG grew between 1994 and 1998 and the universities which were represented regularly at meetings during this period include: Cranfield, Edinburgh, Glasgow, Leeds, London, Manchester Metropolitan, Newcastle, RGU, University College London and Warwick. Representatives from the British Library also participated in the work of the group and, latterly, a representative from the UK Council for Graduate Education became involved.

UTOG is concerned with arrangements relating to online finding aids and access to the abstracts of theses. It is also interested in the production of theses as electronic documents, electronic submission, and issues relating to the assessment and use of electronic theses. Retrospective digitisation and archival and conservation requirements have also been the subject of discussion.

UTOG recognised that most university theses already originate, to some extent, in computer readable form (usually word-processed and often incorporating spreadsheet data and graphs). It also recognised the need for common format standards if 
networked delivery of electronic theses is to be successful. In order to achieve its aims, UTOG identified a number of objectives involving three stages of development. Phase one was for the group to gain an understanding of current patterns of production and use of doctoral theses in the U.K., and to publicise their findings in order to encourage debate. Phase two was to involve the design and implementation of a working demonstrator. Phase three was to focus on persuading universities to accept the submission of theses in electronic format.

In order to gain further information about the production, management and use of theses UTOG conducted a survey involving $2203 \mathrm{PhD}$ students and 1740 supervisors of higher degree students (in eight institutions) plus 125 librarians. The survey involved the use of postal questionnaires and the research was funded by the British Library and Joint Information Systems Committee of the Higher Education Funding Councils (JSC). The British Library Research and Innovation Centre also supported a seminar which took place in London in June 1997 in order to highlight the findings of the research.

The results of the survey are available in the form of a British Library report and on the University of Edinburgh Web pages ${ }^{(2)}$. The questionnaire responses show that for the most part, researchers considered that the theses they had consulted were useful. Many of the researchers replied that they identify potentially useful theses through personal communication rather from a printed or electronic finding aid (thus raising the possibility that other titles might be better used if there is easier access to them). Theses are usually consulted within university departments and libraries, but levels of use do not appear to be monitored adequately. Nevertheless, the information provided by librarians revealed that many of the theses held in their libraries are never read.

The survey results show that most theses are produced initially in electronic format i.e. wordprocessed. A significant percentage include computer software but very few incorporate audio or video recordings. Few of the documents were made available over networks. Yet, with exceptions relating to confidentiality and commercial considerations, the majority of students were positive about their research being published in the form in which it was produced. Taking all these factors into consideration, the findings of the survey appear to support the views of UTOG that it is worth pursuing developments in this area.

UTOG succeeded in achieving its initial objective i.e. of gaining an understanding of current patterns of production and use of doctoral theses in the U.K. and promoting informed discussion on the subject. Members of the group went on to publicise the findings of their research through conference presentations and publications (such as the articles in Program and Ariadne). ${ }^{(3)}$ Unfortunately UTOG has not met since 1998, and, so far, it has not been able to realise the goals it set itself for phase 2 (the design and implementation of a working demonstrator) and phase 3 (an acceptance by universities that theses may be submitted in electronic format). However, the group hopes to reconvene and recommence work in January. (Potential new members are invited to contact the author for further information.)

Other U.K. developments Developments relating to the acceptance of electronic theses in the U.K. are not limited to the work of UTOG. Efforts to promote interest in digital alternatives to paper-based theses are still ongoing in some individual institutions. For example, at The Robert Gordon University a PhD thesis has already been accepted in CD ROM format, and another one is in progress. CD ROM does not allow the flexibility of an online format and, indeed, it may even be more difficult for other researchers to obtain access to this item than to obtain a paper or microfilm copy of a traditionally produced thesis. Nevertheless, this development signifies progress in two key areas: firstly, the student has been able to produce her thesis in its entirety in a form relevant to the subject matter (art and design) rather than having to adapt it to fit a paper-based format and, secondly, the university has reviewed its regulations with a view to making allowances for researchers wishing to exploit the possibilities that are emerging as a result of new technology. In an article published earlier this year, Malins and Gray discuss the key considerations involved in producing a thesis in CD ROM format : the benefits and limitations, the planning required, 
issues relating to structure and content, and the choice of software ${ }^{(4)}$.

(Details of these developments at RGU can be discussed with Julian Malins at

$$
<\text { j.malins@rgu.ac.uk> ). }
$$

Elsewhere, research associated with online $\mathrm{PhD}$ theses and Masters' dissertations is ongoing. For example, at Loughborough University Department of Information Science two postgraduate students are currently engaged in research focused on procedural issues, the role of metadata and preservation needs.

(Further information about these projects may be obtained from Ann O'Brien at Loughborough $<$ A.O-brien@lboro.ac.uk>).

\section{Developments at Virginia Tech.}

The visit Some of the best examples of progress with regard to institutional acceptance of theses and dissertations in electronic format are to be found in the U.S.A. In March 1998, the author visited Virginia Polytechnic Institute and State University (Virginia Tech.) in order to obtain information about the highly successful efforts there - in particular the developments and progress of the Scholarly Communications Project and the Networked Digital Library of Theses and Dissertations initiative.

The background Initial discussions about the possibility of accepting the submission of theses in electronic format took place between the Graduate School and the Library at Virginia Tech. as early as 1993. It was agreed that all of the groups involved . (students, researchers and the Library) could benefit from this development and a task force was formed to pursue the matter. Representatives from key areas within the university were involved in the initial stages: the Graduate School, the Library cataloguing department, I.T. and archives. Due consideration was given to other relevant regional initiatives associated with electronic library developments and there was close liaison with appropriate external organisations such as software suppliers and University Microfilms International (UMI).

Developments The standard which was adopted involved word-processed theses being converted into PDF (Portable Document Format) using Adobe Acrobat software. The theses were made available as web-based documents and attention was given to
Library \& Information Research News (LIRN)

Volume 23 - Number 75 - Autumn 1999

ensuring that security back-up procedures were in place. Initially electronic submission was voluntary - but by 1997, with the approval of the relevant authorities within the university, it had become mandatory. Exemptions were possible, but only in special circumstances, e.g. if the contents of the thesis could not be reproduced digitally in an acceptable fashion. In discussions with members of staff at Virginia Tech. it appeared that one of the key factors in the success of the project was the close co-operation between the Graduate School and the Library. It also became clear that the Library had adapted its workflow arrangements to co-ordinate the various elements involved in the project, and to ensure that the implementation was beneficial to all concerned - faculty, students, administrators, and library users. Support for the project at senior level was also crucial.

Many issues had to be taken into account to ensure that the transition to electronic submission went smoothly. The appropriate software and equipment had to be made available (e.g. Acrobat software was provided in the computer laboratories, and the existence of scanners to convert pictures into digital images was publicised). Training and advice had to be offered to both students and their supervisors, policies and procedures for each stage of the submission had to be worked out, and library cataloguing guidelines had to be updated.

A considerable amount of information about the Scholarly Communications Project at Virginia Tech. is available on the web at $<$ http://scholar.lib.vt.edu/theses/>. Links from this page lead to detailed information for students about how to convert a dissertation into a PDF file and how to submit a thesis, etc. ${ }^{(5)}$ There is also information for those wishing to access, print, or down-load e-theses. Many of the questions likely to be raised by students have been pre-empted by the Virginia Tech. Electronic Theses and Dissertations (ETD) Team, and the web pages give clear advice on many of the potential issues of concern. For example, the page entitled 'Formatting your ETD for submission' provides detailed information relating to page numbering, margin size and acceptable fonts. ${ }^{(6)}$ To help students, an example of a title page is also shown. Other advice pages provide information about the location of laboratories and the availability of equipment for creating multi-media work; recommendations are 
made with regard to the resolution of images and formats for audio material. The provision of this type of detailed online help is one of the factors which has contributed to the success of the scheme at Virginia Tech.

Another factor in the success of the project appears to be the emphasis upon offering students the chance to obtain help with the production of their thesis through attendance at workshops (7) A survey has been undertaken to gain an understanding of the degree of difficulty students experienced in preparing their thesis for submission in electronic format, and the responses have been considered in the light of levels of participation in the workshops. Work is ongoing to monitor issues relating to both the submission and use of the theses at Virginia Tech. and consideration is still being given to the ways in which improvements can be made to the procedures involved.

Levels of use of VT ETDs The statistics relating to the use of Virginia Tech's Doctoral theses and Masters dissertations provide a convincing reason for adopting a web-based electronic format. It is unclear how many of the accesses relate to searches for subject-based information and how many are the result of investigations into the style and presentation of electronic theses. Nevertheless the figures are impressive: the total number of accesses rose from 37,171 in 1996 to 247,573 in 1997 and 666,099 in 1998. ${ }^{(8)}$ Their log files show that in 1996 there were 6294 accesses from outwith the USA. By 1997 the figure had risen to $25,073^{(9)}$ These accesses have a wide geographical spread with over 90 countries represented. Virginia Tech.'s electronic theses and dissertations have been accessed from as far afield as Iceland and Argentina, and from centres of population as varied as the Faroe Islands and Hong Kong. Accesses from the U.K. rose from 850 in 1996 to 2,922 in 1997 and 8,170 in 1998.

By March 1999, 1,578 ETDs had been submitted to, and approved by, Virginia Tech.'s Graduate School and, of those, 1,272 were unrestricted and available online. (Students are required to submit an 'Electronic Submission Approval Form' which includes a declaration that copyright clearance has been obtained and an agreement about the extent to which the thesis may be made available to others readers e.g complete release of the work allowing access worldwide, limited access restricting use to the Virginia Tech. campus, or all access denied for two years).

The server logs reveal, on a search of U.S. domains, that the accesses between 1996 and 1998 came from a wide variety of sources: education, commercial, government, military, networks and non-profit organisations. The individual theses most frequently accessed in 1997 and 1998 originated in the departments of engineering, physics and computer science. However, in 1998 an interior design thesis was listed in the 'top ten'. The detailed statistics being kept by Virginia Tech. and publicised on their web pages provide a valuable insight into which theses are most used. (This information may be useful to universities which are considering undertaking a pilot study to assess the value of making theses available in electronic format).

NDLTD: The establishment of the Networked Digital Library of Theses and Dissertations (NDLTD) Initiative allowed the Virginia Tech. team to develop further their interests in the area of electronic theses.

The NDLTD describes itself as a federation of member universities with a number of aims and objectives including the advancement of digital library technology and the increase in availability of student research ${ }^{(1)}{ }^{2}$ The Spring 1998 meeting of the Steering Group of the NDLTD was attended by representatives from Virginia Tech. and other U.S. universities, the National Library of Canada, the Council of Graduate Schools (CGS), the Coalition for Networked Information (CNI), the Association of Research Libraries (ARL), University Microfilms International (UMI), IBM and Adobe Systems. By Autumn 1999 other major organisations, including UNESCO, were also demonstrating an interest in the project ${ }^{(11)}$

A list of NDLTD news articles and press releases is given at $<$ http://www.ndltd.org/news/index.htm $>$.

The list of 'Official University Nodes in the NDLTD' listed on the web page $<$ http://www.theses.org $>$ illustrates the range of organisations having an interest in this initiative. The list of official members of the NDLTD (57 
universities and 6 other institutions) now includes organisations from a wide range of countries including Australia, Canada, Germany, India, Russia, Spain, and South Africa - as shown on the web page

$<\underline{\text { http://scholar.lib.vt.edu/theses/NDLTD/members.ht }}$ $\underline{m l}>$.

\section{Conclusion}

A vast amount of work relating to the development of electronic theses has already been undertaken in the USA. and many of the key procedures involved have been documented and made available on the web. With such useful information already available it may be appropriate for the U.K. group UTOG to liaise more closely with Virginia Tech. and the NDLTD. Rather than spending time on developing a prototype demonstrator, UTOG's efforts might be better directed towards what they defined as phase three of their project i.e. creating a culture change within U.K. universities with regard to the acceptance of theses in electronic format.

Institutions could be encouraged to consider how the Virginia Tech. model might be adapted to suit local circumstances. Clearly there are differences between the situation in the U.S. and that in the U.K., and some significant decisions remain to be made - for example, in terms of arrangements with the British Library British Thesis Service. However, the Virginia Tech. team has overcome many of the problems associated with such an initiative, and the growth of the NDLTD project is evidence of international interest in such developments.

The technology involved in the creation of online theses is the same regardless of whether the work is at doctoral or masters level. In the UK UTOG is currently concentrating on issues relating to $\mathrm{PhD}$ theses. But, with many university libraries no longer prepared to retain copies of masters dissertations, it may be timely to consider developments in a broader context. Access to theses could become more fragmented than at present, and controls on authenticity could be problematic, if individuals simply make theses available on their own web pages. A systematic approach, incorporating an appropriate approval mechanism, is required if future developments are to be successful.
Library \& Information Research News (LIRN)

Volume 23 - Number 75 - Autumn 1999

If electronic theses are made available on the World Wide Web, they should be organised in a way that allows them to be located easily. Ideally, a federated search of all online theses by title, abstract, or full text, would enable researchers to obtain access to all relevant publications regardless of the institution of origin. Existing expertise within the U.K. has to be shared if progress in this area is to be achieved.

\section{References}

I.http://www.cranfield.ac.uk/library/utog/

2. Roberts, A. Survey on the use of doctoral theses in British universities. Edinburgh: Edinburgh University Library, 1997. (British Library Research and Innovation Report 57). http://libcd2.lib.ed.ac.uk/Theses

3. Lomax, J.The work of the University Theses Online Group : report of a survey and seminar. Program. 3l (4) 1997. pp377-382.

Roberts, A. Theses unbound. Ariadne. Issue II. September 1997.pI.

4. Malins, J. and Gray, C. The digital thesis : recent developments in practice-based $\mathrm{PhD}$ research in art \& design. Digital creativity. 10 (I) 1999. pp |8-28.

\section{5. http://etd.vt.edu/submit/index.htm}

6.http://etd.vt.edu/submit/format.htm

7. http://etd.vt.edu/workshop/index.htm

8. http://scholar.lib.vt.edu/theses/data/somefacts.html

9. http://scholar.lib.vt.edu/theses/data/coun 9697 htm

10. http://www.ndled.org/

II. http://scholar.lib.vt.edu/theses/NDLTD/ 